Ciudad y territorio 


\section{Una mirada polisémica de la ciudad de Barva, Costa Rica}

MSc. Marcela Otárola Guevara, Arquitecta

Invitada nacional

Profesional independiente

motarolag@gmail.com

Recibido: marzo del 2016

Aceptado: mayo del 2016

Ciudad y territorio

Investigación 


\section{Resumen}

Este es el resumen de una tesis presentada en el 2015 para optar al grado de Magister Scientiae en Historia Aplicada en la Universidad Nacional. Es una investigación de Historia Urbana sobre la transformación espacial del Distrito Central de Barva en el período 1945-2014, producto de los cambios en su población. Se considera la ciudad un elemento sígnico que revela los pensamientos que han primado en su modelaje urbano y que se manifiestan en la apropiación de los espacios arquitectónicos. El objetivo del estudio es explicar la morfología social y urbana como el resultado de la interacción de actores sociales y dilucidar su procedencia; la metodología empleada incluyó la revisión documental de fuentes diversas (fotografías, censos, mapas, actas, crónicas, españolas) y un trabajo de campo (observaciones no participantes y entrevistas) que fueron sistematizados en sinopsis, cuadros y mapas conceptuales. Tras el análisis de los resultados se descubrió que: a) Barva se ha apreciado como un pueblo agropecuario e indígena desde el período de la colonia, b) los cambios en la población han provocado reacciones en los habitantes que se expresan en prácticas urbanas particulares, c) la valoración urbana está asociada a representaciones sociales devenidas del uso cotidiano de los espacios y de antiguas creencias y d) el desarrollo territorial y el paisaje urbano son expresiones del comportamiento social en diferentes coyunturas. Se concluye que el Distrito Central de Barva ha cambiado porque su población lo ha hecho y por tanto los procesos de construcción identitarios se han modificado.

Palabras clave: forma social; historia urbana; morfología urbana; representaciones sociales; significantes urbanos. 


\begin{abstract}
This is the summary of a thesis presented in 2015 for the degree of Master of Science in Applied History at the National University. It is an investigation of the urban history of the spatial transformation of the Central District of Barva in the period from 1945 to 2014, as a result of changes in its population. The city is treated as a symbolic element that reveals the thoughts that have prevailed in its urban modeling and manifested in the appropriation of architectural spaces. The aim of the study is to explain the social and urban morphology as consequence of the interaction of social actors and elucidate its origin; the methodology used included the review of documents from various sources (photographs, censuses, maps, records, Spanish chronicles) and fieldwork (nonparticipant observations and interviews) that were systematized in synopsis, tables and conceptual maps. After analysis of the results it was found that: a) Barva has been appreciated as an agricultural and indigenous place since the period of the Colony; b) changes in the population have provoked reactions in people who have particular urban practices; c) urban assessment is associated with social representations that come from uses of everyday spaces and ancient beliefs and d) territorial development and urban landscape are expressions of social behavior in different situations. It is concluded that the Central District of Barva has changed because its population has changed and, therefore, identity construction processes have been modified.
\end{abstract}

Keywords: significant urban; social form; social representations; urban history; urban morphology. 


\title{
Una mirada polisémica de la ciudad de Barva, Costa Rica
}

\author{
Marcela Otárola Guevara ${ }^{1}$
}

\section{Introducción}

Por su naturaleza inacabada, la ciudad es un objeto de estudio muy generoso que brinda múltiples temas de investigación. Sus hacedores, los ciudadanos, la modifican y reformulan según las contingencias de la época estableciendo dinámicas que han sido analizadas por investigadores de diferentes disciplinas de la ciencia social. Desde esta perspectiva, la arquitectura constituye un campo importante de reflexión pues, al concebirse la edificación (tangible e intangible) como materialización de la acción humana, es posible vislumbrar el pensamiento de una colectividad a través de la interpretación de los espacios que configuran una urbe.

Consecuentemente con este enfoque existen estudios sobre el "espacio social" o "la forma espacial de la ciudad" (Harvey, 1977, p.20), pero pocos donde se aprecie un abordaje que complemente ambas visiones, razón por la cual se procedió a realizar una pesquisa sustentada en el análisis de la arquitectura como un "vehículo sígnico" (Eco, 1978, p.331). Para ello, se escogió una comunidad que se ha transformado espacialmente de manera acelerada en las últimas tres décadas: Barva, específicamente el distrito central del cantón que lleva el mismo nombre y se ubica en la provincia de Heredia, Costa Rica.

Sobre el devenir de este poblado hay diversos textos que narran su historia; desde su origen como comunidad indígena descrita en documentos coloniales hasta su consolidación como territorio agrícola (esencialmente cafetalero) en los siglos XIX y $\mathrm{XX}$, según consta en censos agrícolas, revistas agrarias y monografías. No obstante, se ha encontrado en recursos visuales como imágenes aéreas, mapas y fotos de la ciudad de distintas épocas, otra veta de información que expone los procesos socioeconómicos que la han conformado. Concatenando los insumos que brindan estas fuentes y complementando, además, con datos obtenidos de entrevistas hechas a informantes barveños representativos, se ha logrado formular una explicación sobre la mutación de la ciudad empleando la arquitectura como exégesis e ilustración.

\footnotetext{
1 Magister Scientiae en Historia Aplicada, arquitecta, profesional independiente, investigadora en Historia Urbana, Costa Rica, motarolag@gmail.com. La autora agradece a la Dra. Carmen Araya Jiménez, al Dr. Carlos Hernández y a la M.Sc Lidia Orias, las contribuciones en la conducción del estudio que sustentó este artículo.
} 


\section{El objeto de estudio}

En esta localidad las actividades económicas, políticas e ideológicas se concentraron en un nodo y definieron una centralidad que forjó el embrión de la ciudad actual. Este se ubicó en el Distrito Central de Barva, se fundó esencialmente en el conjunto compuesto por la Iglesia de San Bartolomé, el parque (originalmente plaza) y el edificio municipal, y tuvo una condición convergente que aglutinó tejidos urbanos y sociales distinguiendo el sitio como el Locus ${ }^{2}$ de la comunidad. Por estas características, en ese sitio se seleccionaron 16 cuadras como área de investigación y se tomó el período 1945-2014 como delimitación temporal, pues en ese lapso han ocurrido las permutas urbanas más significativas.

Consecuentemente, por concebirse la ciudad como una construcción social, se determinó como objetivo general del trabajo explicar la relación entre la gestión de actores sociales de la localidad y el cambio urbano distrital y, así, comprender las acciones transformadoras de la ciudad, apreciar su impronta en el ordenamiento territorial e interpretar su mediación en la percepción de sus habitantes. Para lograr esta meta se precisaron los alcances específicos que se describen a continuación y en torno a ellos se organizó la información y los hallazgos encontrados:

- Identificar los eventos históricosque perfilaron a la población de Barvay determinar en ellos los mecanismos de apropiación del lugar donde se situó el asentamiento.

- Establecer cómo actúan los principales actores sociales y como su comportamiento modela la fisonomía social y urbana de la población en estudio.

- Determinar las representaciones sociales que priman en la mentalidad de los habitantes barveños y la forma cómo ellas se proyectan en la ciudad.

- Mostrar las principales características arquitectónicas del centro de Barva, sus modificaciones y lo que simbolizan, para interpretar los patrones geométricos y de acontecimiento vigentes en la ciudad.

2 Término empleado en arquitectura para expresar la relación existente entre las construcciones y las vivencias humanas de una localidad, revelando la vinculación del individuo con su entorno. En esta interacción intervienen afectos, ideas y percepciones hacia un territorio, instaurando en él una particularidad que lo hace reconocible y único. 


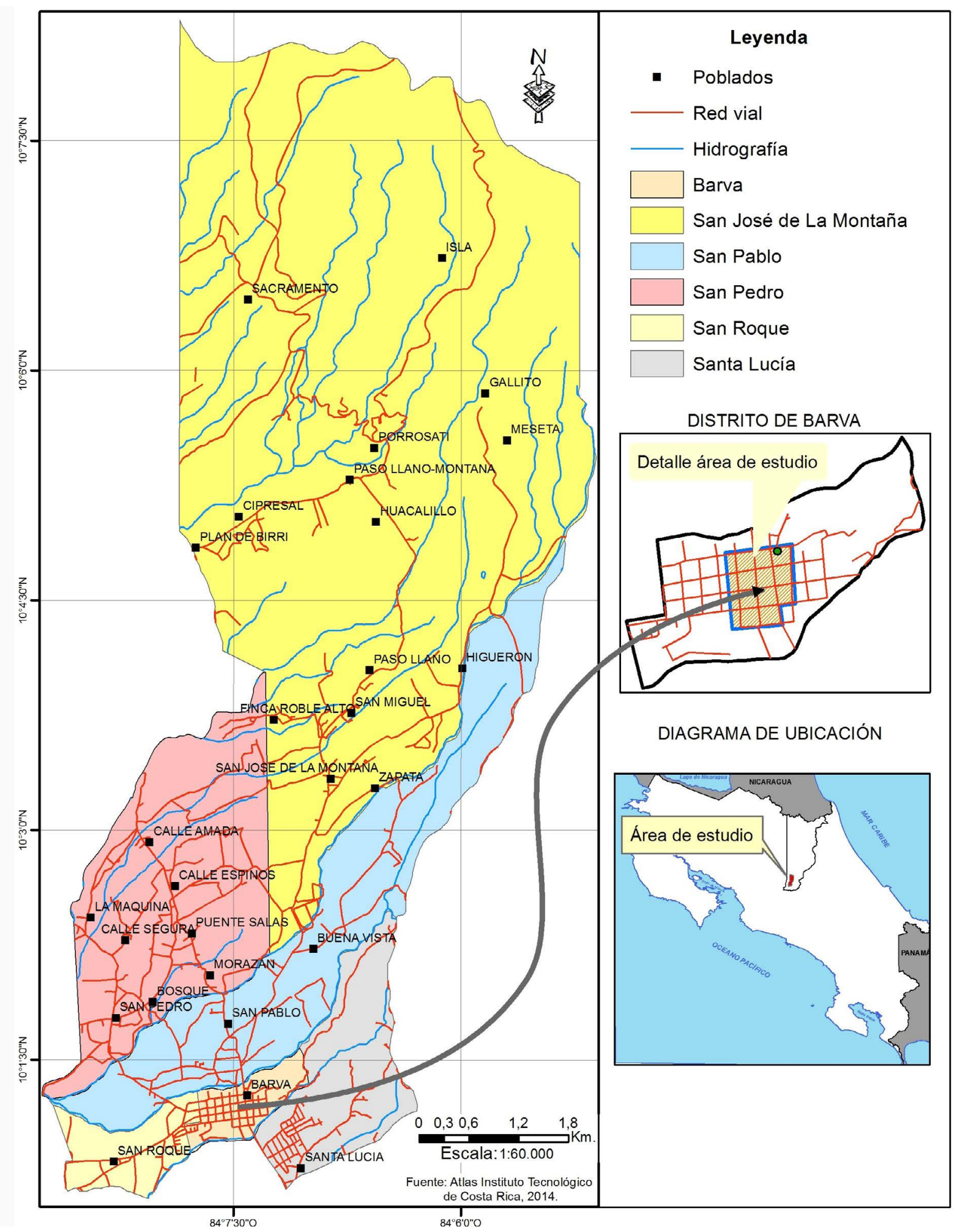

Figura 1. Ubicación del área de estudio. Fuente: Instituto Tecnológico de Costa Rica.

\section{Perspectiva teórica}

La investigación efectuada espacializa las relaciones humanas que ocurren en un lugar y que otorgan importancia al "dónde" (Oyón \& Serra, 2012, p.388). Este enfoque es propio de la Historia Urbana, campo que trata los cambios en las ciudades examinando su tejido arquitectónico, mismo que no se concibe como un fin sino como un medio para descubrir lo que se esconde tras su apariencia.

La urdimbre espacial de una urbe expone simultáneamente una configuración social y física, siendo la morfología urbana el referente teórico e integrador que permite abordar el estudio de los poblados considerando su distribución territorial, su historia 
y la percepción de sus habitantes. Esta visión fue formulada en los años setenta por geógrafos humanistas interesados en atender temas como "la recuperación del lugar urbano, la preocupación por el paisaje existencial o la rehabilitación de los centros históricos" (Bielza de Ory, 2011, p.39). Uno de sus exponentes más representativos es el geógrafo Horacio Capel (citado en Sánchez, 2004) quien declara: "la ciudad es la forma más excelsa de paisaje cultural" (p.19) y agrega que la parcelación, la edificación y los usos del suelo son variables que permiten reconocer una realidad, a la vez que incorpora la revisión historiográfica como estrategia para elucidar las razones que explican su composición.

De esta forma, la fisonomía territorial se presenta como resultado de una construcción social devenida a lo largo del tiempo. Es reconocible por su figura y por las interacciones quela han generado e integran la estructura urbana, concepto que usa el sociólogo Manuel Castells (1974) para referirse a la red de relaciones de la que emerge la organización de una comunidad y que le otorga una especificidad, es decir, rasgos propios que se desprenden de un tipo de relación (o de su combinación) que él denomina sistemas y los cataloga en económico, político-institucional e ideológico. Interesa ahondar en esta última categoría (lo que no implica la exclusión de las otras) por la conceptualización que el autor plantea del espacio como palestra de enunciación de discursos ideológicos, connotación inferida de la aseveración que realiza: "Existe simbólica urbana a partir de la utilización de las formas espaciales como emisores, retransmisores y receptores de las prácticas ideológicas generales" (p.259).

Así, el espacio arquitectónico emprende lo que el semiólogo Umberto Eco (1978) llama "finalidades comunicativas" (p.341), es decir, se convierte en un objeto que denota una función y connota un significado cuyo contenido puede ser reproducido, modificado, descartado o suplantado según el bagaje de quien lo percibe e interpreta, dado que está asociado a coyunturas históricas determinadas. Por tanto, la ciudad además de comportar una red de relaciones sociales y significados, también sobrelleva un sistema cognitivo que facilita su interpretación pues comprende las valoraciones que hacen los usuarios de un determinado espacio.

Esas percepciones han sido llamadas representaciones sociales, concepto de Sergei Moscovici y retomado por la socióloga Sandra Araya (2002) para referirse al conjunto de manifestaciones culturales que son compartidas, conforman la cosmovisión de una colectividad y proporcionan un sentido de orden a la realidad. Esta investigadora establece que tales representaciones se anclan en el individuo de distintas formas, siendo una de ellas la objetivación: proceso reflexivo en el que lo abstracto se reduce a una 
materialización específica. En el caso particular de la arquitectura, la materialización de una idea se lleva a cabo mediante la apropiación espacial que concede un valor simbólico a los lugares y provoca apego socio territorial.

Ahora bien, ¿cómo se esclarecen los símbolos en el espacio urbano? La estrategia diseñada por Araya para identificar las representaciones sociales es una guía apropiada, pues se sustenta en la respuesta de las preguntas ¿qué se sabe?, ¿qué se cree o se interpreta? y ¿qué o cómo se hace? que implican un contacto directo con el objeto de estudio mediante la consulta documental, la visita recurrente al sitio y el diálogo con los ciudadanos barveños; concertando un reservorio de datos provenientes de fuentes heterogéneas. Ante esta circunstancia, los referentes teóricos citados componen una perspectiva que faculta la comprensión de los aspectos de la mentalidad que conducen la cotidianidad urbana.

\section{Metodología}

Esta investigación es una indagación retrospectiva que integró la revisión documental con el trabajo de campo implicando la consulta de fuentes de diversa naturaleza y formato. Según su contenido se clasificaron en:

- Fuentes primarias: incluyeron entrevistas a líderes comunales, conversaciones informales con residentes, actas municipales, censos agropecuarios y poblacionales, crónicas españolas, fotografías aéreas, de la ciudad y sus moradores; mapas censales, observaciones del trabajo de campo, panfletos y artículos de periódicos cantonales y provinciales.

- Fuentes secundarias: contuvieron monografías del cantón (1924, 1964 y 1997), programas de ordenamiento territorial como el Plan Regulador de Barva (2006) y el Manual de Procedimiento para edificaciones patrimoniales en Barva, inventarios culturales y artículos historiográficos.

La metodología se organizó siguiendo el orden y los alcances de los objetivos específicos y, para cada uno de ellos, se consultó y exploró información concerniente a su tema central lo que demandó el empleo de técnicas particulares de recolección y sistematización. 
El primer objetivo de la pesquisa trató sobre los antecedentes de Barva. La información se obtuvo de monografías, artículos de periódicos provinciales y panfletos facilitados por barveños reconocidos como compiladores de la historia del cantón; se entrevistó a profesores universitarios que han investigado la localidad y ellos refirieron a crónicas españolas y censos de los siglos XIX y XX resguardados en el Archivo y en la Biblioteca Nacional. Otros textos hallados en bibliotecas de la Universidad Nacional y en Internet complementaron los datos y ayudaron a su interpretación. Tras la lectura de los escritos, éstos se resumieron, se clasificaron según el impacto social de los hechos narrados, se dispusieron cronológicamente y se formuló un esquema de ideas donde las más relevantes se concatenaron en un mapa conceptual; consiguiéndose una depuración de los acontecimientos que dejaron huella en el devenir del objeto de estudio.

El segundo objetivo abordó el tema de la población y para visualizar su comportamiento se acudió al Instituto Nacional de Estadística y Censos (INEC). Allí se consiguieron registros sobre características demográficas del cantón y mapas que muestran los usos del suelo dados al territorio en diferentes épocas. Esta información se vinculó con imágenes aéreas adquiridas en el Instituto Geográfico Nacional (IGN) y con fotografías de colecciones privadas y públicas de ciudadanos barveños que sirvieron para ilustrar los datos censales. También se consultó el Plan Regulador de Barva (2006) suministrado por el Departamento de Bienes Inmuebles y Catastro de la Municipalidad de Barva, y en él se notó la composición social reciente de los distritos del cantón. Así mismo, se realizó un trabajo de campo basado en observaciones no participantes en eventos comunales, con el fin de identificar las relaciones entre los habitantes y sus formas de apropiación del espacio urbano; actos que quedaron presentados en notas y fotografías consignadas en una bitácora de campo y que posteriormente se ordenaron por tópicos. De cada fuente se realizó un resumen subrayando los hechos relevantes y los actores sociales involucrados. Estos datos se organizaron por períodos, se ubicaron en una línea de tiempo para cotejarlos y apreciar la transformación de la comunidad, se hicieron observaciones y se articularon en un esquema del que se obtuvo un perfil de la población, un recuento de agentes urbanos y de sus prácticas en los espacios públicos.

Para conocer las representaciones sociales de los ciudadanos, propósito del objetivo tres, se entrevistaron informantes claves de la comunidad. Estas personas fueron seleccionadas por recomendación de funcionarios municipales y miembros de asociaciones vecinales, por haber vivido en Barva en periodo prolongado y ser líderes de opinión. La interlocución se hizo basada en una guía con preguntas abiertas sobre antecedentes de la persona, lugares emblemáticos, tradiciones y costumbres locales. Luego, las conversaciones fueron grabadas, transcritas y sintetizadas en fichas; éstas se 
analizaron y de ellas fueron sustraídos los vocablos de mayor mención en cada plática. Seguidamente los términos se tabularon en un cuadro, se escogieron los coincidentes entre los entrevistados y se examinaron nuevamente considerando el discurso que los enunció, usando como referencia la estrategia antes citada por Sandra Araya para establecer el campo de las representaciones sociales y su sentido. El resultado alcanzado consistió en la identificación de términos claves, discursos y valoraciones que priman en la mentalidad de la comunidad.

La meta del objetivo cuatro fue visualizar los cambios urbanos y para ello se emplearon fotos de dos clases: a) tomas aéreas suministradas por el IGN y con las que se elaboraron mapas del crecimiento urbano mediante georeferenciación y b) tomas humanas de gente y su cotidianidad, el paisaje urbano y eventos tradicionales, adquiridas de libros y colecciones privadas y públicas. Complementariamente, se examinaron documentos relacionados con ordenanzas territoriales e inventarios inmobiliarios para comprender la asociación entre el comportamiento del uso del suelo y los procesos de urbanización. Mapas, fotografías y notas documentales fueron sistematizados por periodo tomando como referencia los años de las imágenes aéreas, luego se ordenaron por tema y se compararon con los términos significativos encontrados en el apartado del objetivo tres. Las temáticas más relevantes se seleccionaron y jerarquizaron según su impacto en la conformación morfológica de Barva, luego los descubrimientos se ordenaron en cuadros comparativos y mapas conceptuales y así se determinó una cronología que mostró las permutas sociales y urbanas del objeto de estudio.

\section{Resultados y sus análisis}

La investigación mostró los siguientes resultados: a) identificó eventos que han incidido en la forma social y urbana de Barva, b) precisó los actores sociales y las estrategias que usaron para modificar la ciudad, c) reveló las ideas que dan un sentido de orden y arraigo a la comunidad y d) advirtió los cambios arquitectónicos como expresión de la transformación de la gente.

a) Entre los eventos históricos que configuraron la morfología de Barva hay tres que destacan:

- $\quad$ Fundación de Barva como pueblo de doctrina (S.XVII-S.XIX). Crónicas españolas y otros textos históricos señalan que el Valle de Barva estuvo habitado por indígenas güetares y votos, quienes fueron dominados por los españoles en el siglo XVII a través de la Cofradía; institución que instauró un nuevo orden social, forjó una identidad 
religiosa centrada en la fe católica y administró el territorio y sus cosechas. De esta forma se concibió el embrión de un poblado que se consolidó cuando la Iglesia Católica, para descentralizar los actos litúrgicos en Cartago, fundó ermitas en varios poblados de la provincia, naciendo así San Bartolomé (actual Barva) como un pueblo de doctrina dirigido por sacerdotes franciscanos quienes crearon una comunidad caracterizada por la obediencia a la autoridad, la homogenización de los lugareños por su linaje indígena y el ejercicio subordinado de oficios, en su mayoría agrícolas. La institución religiosa mantuvo su preeminencia mediante prácticas urbanas que impulsaron la cohesión vecinal, pues ellas abrieron significativos espacios de socialización en áreas públicas erigiendo el Locus: ese lugar simbólico de enunciación del apego socio territorial que lo hace reconocible y único, y donde se forjó el principio de un centro urbano que hoy pervive.

- $\quad$ Separación de Cubujuquí del Valle de Barva (S.XVII-S.XIX). En el Valle de Barva también se fundó el pueblo de Cubujuquí "a un cuarto de legua de distancia" (Solera, 1964, p.15) de San Bartolomé y, al igual que este, tuvo un rol importante en la actividad agropecuaria provincial (figura 1). Ambos sitios fueron zonas muy productivas pero su desarrollo tomó direcciones distintas debido a la naturaleza de sus habitantes. Mientras que los de San Bartolomé eran indígenas nativos y trabajadores supeditados, considerados por los hispánicos como bárbaros e incapaces de aprovechar eficazmente la tierra ; los de Cubujuquí eran de linaje español que arribaron a la zona en el siglo XVII (Bolaños \& Valverde, 1978), traían consigo el estigma de portadores de progreso por la experiencia de conquista de sus ancestros, y eran dueños de fincas y otros recursos productivos. Estos últimos ordenaron la urbe siguiendo una estratificación socio-racial, donde los de mayor jerarquía habitaron en los alrededores de la iglesia, misma que fue declarada parroquia independiente en 1734 , conformando un sitio al que fueron conminados a vivir los colonos del Valle de Barva con el fin de congregar la cantidad necesaria de vecinos para otorgarle el título de villa, meta alcanzada en el año 1763 y que le valió la designación de Villa de la Inmaculada Concepción de Cubujuquí de Heredia (Dobles \& González, 1934). 


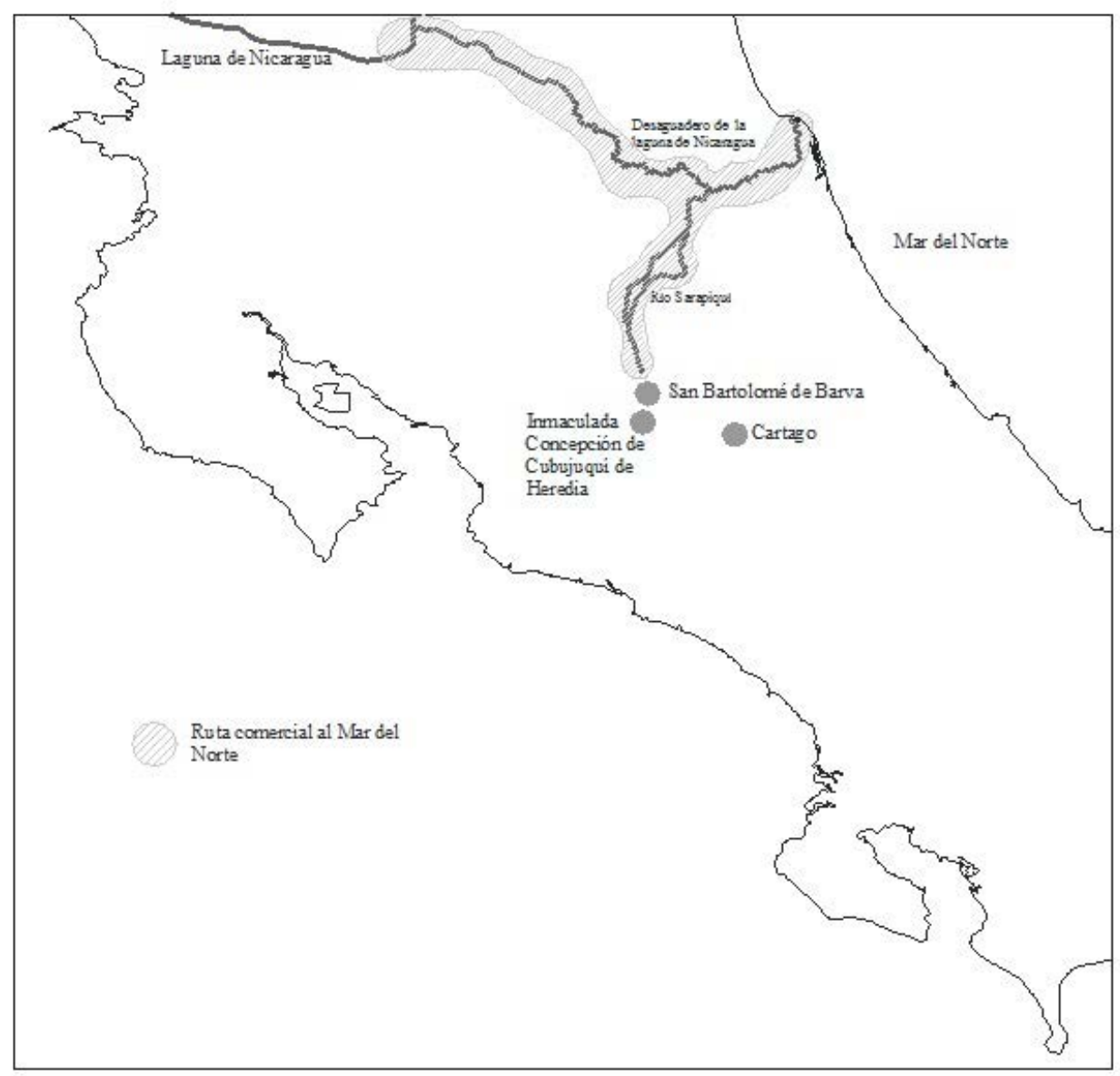

Figura 2. Ubicación de San Bartolomé y Cubujuquí en la provincia de Heredia en el siglo XVIII. Fuente: Información obtenida del artículo elaborado por la Arq. Rosa Malavassi y titulado: Órdenes franciscana y mercedaria en la Diócesis de Nicaragua y Costa Rica en el siglo XVIII: su arquitectura y la ocupación del espacio.

Documentos coloniales relatan este proceso y también revelan la pugna por tierra entre las dos localidades. Los moradores de San Bartolomé acudieron a las autoridades políticas y atribuyeron a los de Cubujuquí la usurpación de sus tierras (dada la cercanía entre ellas), denuncia rebatida por los últimos y que sirvió para exponer otredades que perfilarían a los ciudadanos de los pueblos en cuestión: los colonos españoles y mestizos se diferenciaron de los naturales de la comarca señalándolos como bárbaros, mentirosos e ineficientes, características opuestas a ellos que se consideraron ciudadanos de buenas costumbres y con proba capacidad para repoblar exitosamente. Bajo esta perspectiva se continuó la expropiación de campos de indígenas y se robusteció una relación de poder sustentada en la tenencia de tierra, hechos que fueron refrendados legalmente y legitimaron relaciones sociales y económicas desiguales.

Con el otorgamiento del título de villa a Cubujuquí, esta se separa del Valle de Barva y adquiere una posición prominente que revalida estigmas que trascienden al conglomerado social: Cubujuquí se concebirá como el afincamiento de una élite económica y social, mientras que San Bartolomé como un territorio de naturales que requieren ser civilizados. De tal modo, se establece una relación centro periferia que se materializó en el siglo XIX cuando se crea la provincia de Heredia con dos cantones Barba (antes San Bartolomé) y Heredia (antiguo Cubujuquí) como cabecera provincial (Dobles \& González, 1934). Esta relación de predominio está vigente en el imaginario 
barveño y se manifiesta recurrentemente en revisiones bibliográficas del siglo XX y en entrevistas a pobladores.

- Conformación de Barva comozona agropecuaria(S.XIX-S.XX). Con el advenimiento de la Independencia de España en el siglo XIX, en San Bartolomé se instauró el ayuntamiento (nueva forma de gobierno local) el cual asumió la administración de los antiguos lotes tutelados por las cofradías y los alquiló a aparceros, quienes se convirtieron en sus dueños legítimos mediante una ley promulgada en el año 1835 (Bolaños \& Valverde, 1978). Algunas propiedades fueron dedicadas a la agricultura pero, las aledañas a la Iglesia y a la plaza del pueblo, fueron adquiridas por un grupo dominante descendiente de antiguos colonos (del cual, posteriormente, surgieron líderes políticos como el ex presidente Cleto González Víquez) quienes edificaron allí sus casas. Se formó un nodo donde confluyeron una élite política y otra religiosa; y ellas promovieron allí la construcción de importantes obras de infraestructura como la escuela, el alumbrado eléctrico y el empedrado de calles, dando cuerpo a un centro urbano.

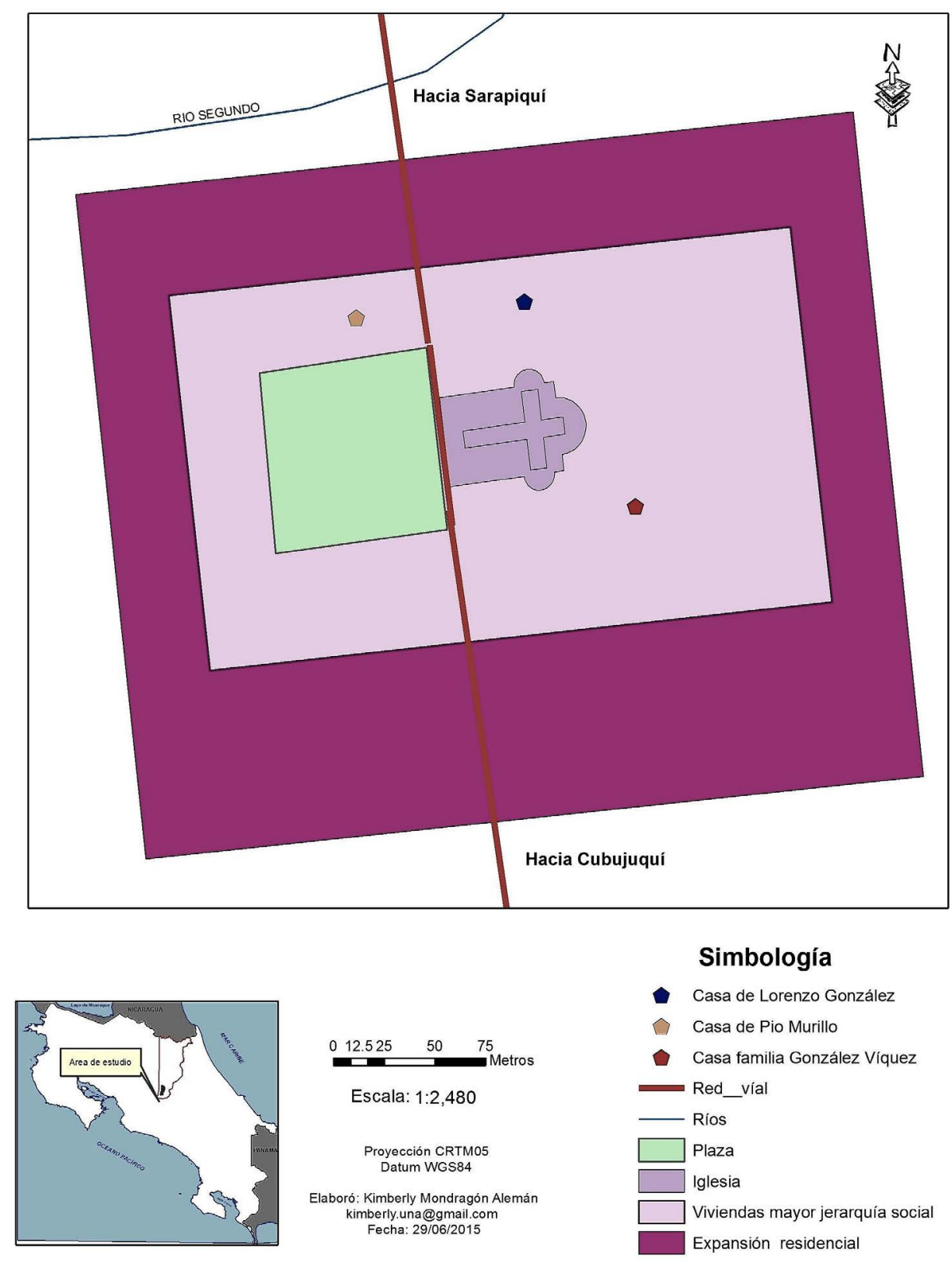

Figura 3. Configuración del centro urbano de Barva en el siglo XIX. Fuente: Elaboración propia hecha con datos obtenidos del texto: Índice de los Protocolos de Heredia, 1721-1851, Archivos Nacionales de Costa Rica (1904). 
Por otra parte, las políticas económicas del nuevo Estado costarricense impulsaron el cultivo del café para la exportación, iniciativa que tuvo acogida en el Valle de Barva y modificó el uso forestal de su suelo pues zonas boscosas, de pastoreo y agrícolas de pequeña escala (maíz y frijol) se sustituyeron por sembradíos del grano (Blanco, 2011). Surgieron lugares perimetrales a San Bartolomé (llamado Barva en el siglo XX) como San Pedro y San Pablo, que destacaron como localidades productivas cafetaleras y demandaron caminos para el trasiego de estas y otras cosechas (como la caña); configurándose una red de vías que favoreció la integración de los poblados de la zona y creó una zona agropecuaria. El núcleo de esta área se ubicó en el conjunto espacial compuesto por la Iglesia, la plaza y la Municipalidad (anterior ayuntamiento), punto de partida de la retícula urbana y nudo de interrelaciones que se incrementaron e intensificaron a partir de la década de 1950 como consecuencia de las migraciones provocadas por la "metropolización" (Carvajal, 2005) en la Gran Área Metropolitana (GAM).

b) Los actores sociales que han modificado el espacio urbano barveño han sido el gobierno local, la Iglesia Católica, desarrolladores inmobiliarios, comerciantes, asociaciones artísticas, gestores culturales, habitantes oriundos y migrantes. Su intervención se aprecia en los siguientes hechos:

- Transición en el territorio de lo rural a lo urbano. Hasta la mitad del siglo XX Barva fue un asentamiento rural de producción cafetalera y ganadera, situación que se modificó perceptiblemente en la década de los años setenta por la baja en los precios del café y por la presión demográfica resultante de migraciones internas en la GAM. Registros censales revelan la existencia de una población homogénea; la mayoría eran naturales del lugar $(68.73 \%)^{3}$ y se dedicaban a labores agropecuarias, condición que se mantuvo así en los años sesenta. Fotos aéreas del cantón de 1945 y 1960 muestran una cobertura agrícola amplia en la cabecera cantonal, las calles como ordenadores de ejidos y un exiguo núcleo urbano basado en la Iglesia, la plaza y el edificio municipal. A partir de 1970 los censos demográficos exponen un aumento de residentes en el distrito central (25,38\%) y lo catalogan urbano por la densificación en cuadras céntricas de áreas comerciales, de servicios y residenciales. Así mismo, entre 1990 y el 2010 localidades circunvecinas como San Roque, San Pablo y San Pedro se extendieron impulsadas por el desarrollo de proyectos inmobiliarios, borrando los límites entre las comunidades y generando una conurbación dentro y fuera de Barva, circunstancias que formaron una urbe que, para el siglo XXI, tendrá una morfología urbana y social heterogénea.

3 Información obtenida del Censo de Población de Costa de 1950 llevado a cabo por la Dirección General de Estadística y Censos. 


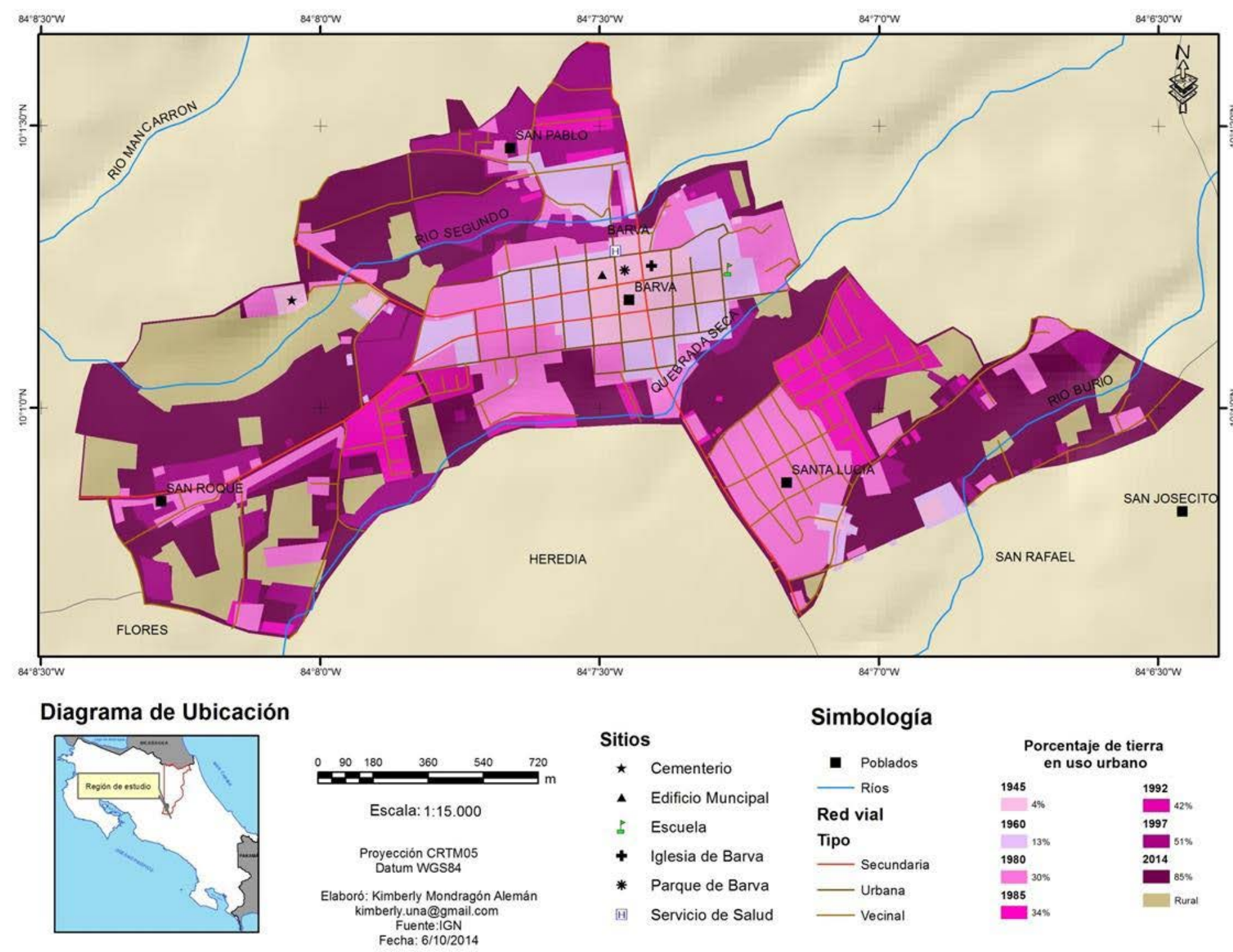

Figura 4. Expansión del espacio urbano en el distrito central de Barva entre 1945 y 2014. Fuente: Fotografías aéreas del Instituto Geográfico Nacional.

c) Transformación del centro urbano: el espacio residencial cambia a comercial. La oferta de vivienda ampliamente desplegada por desarrolladores inmobiliarios, la prestación de servicios urbanos, una infraestructura institucional consolidada y una vasta red vial, son factores atractivos que propician una profusa migración hacia Barva a finales del siglo XX e inicios del XXI. Entre 1984 y el 2011 el cantón aumentó su cantidad de habitantes en un 114,76\% (tabla 1), muchos de ellos llegaron para trabajar en nuevos centros de trabajo heredianos y se radicaron en distritos periféricos (San Roque y Santa Lucía principalmente). Barva, el distrito central, mantuvo un $67 \%$ de su población oriunda; empero, esta situación se ha transformado porque su uso residencial ha mutado a mercantil debido a comerciantes foráneos quienes, interesados en satisfacer la demanda de bienes y servicios de un número mayor de nuevos moradores, compran propiedades en la jurisdicción para instalar negocios, estableciendo nuevas formas de apropiación espacial urbana que desplazan prácticas tradicionales de cohesión comunitaria y que promueven una construcción social de la ciudad donde prima el utilitarismo comercial. 
Tabla 1. Comparación de cantidad de habitantes de Barva entre los años 1984 y 2011

\begin{tabular}{|c|c|c|c|c|c|c|c|c|c|}
\hline & & \multicolumn{2}{|c|}{ No migrantes } & \multicolumn{2}{|c|}{ Migrantes (total) } & \multicolumn{2}{|c|}{ Migrantes internos } & \multicolumn{2}{|c|}{ Migrantes externos } \\
\hline & & (\#) & $(\%)$ & (\#) & $(\%)$ & (\#) & $(\%)$ & (\#) & $(\%)$ \\
\hline Barva (1984) & 18,933 & 11,286 & 59.6 & 7,647 & 40.4 & 7,332 & 95.88 & 315 & 4.12 \\
\hline Barva (2011) & 40,660 & 21,616 & 53.2 & 19,044 & 46.8 & 16,856 & 88.51 & 2,188 & 11.49 \\
\hline Incremento $\%$ & 114.76 & 91.53 & & 149.04 & & 129.90 & & 594.60 & \\
\hline \# veces incremento & 1.15 & 0.92 & & 1.49 & & 1.30 & & 5.95 & \\
\hline
\end{tabular}

Fuente: Elaboración propia basada en censos de población de los años 1984 y 2011 realizados por el INEC.

d) Preservación de actos religiosos y populares como insignias identitarias. La enajenación de la tierra y la presencia de nuevos habitantes han provocado actos de resistencia que tienen lugar en el Locus, punto de confluencia donde se han preservado costumbres, se han resemantizado unas e instaurado otras, como resultado de la gestión de dos tipos de actores sociales quienes expresan en ellas lo que consideran es la idiosincrasia barveña: un grupo de ellos está conformado por instituciones que han detentado el poder, han intervenido en el desarrollo de la infraestructura urbana y desean controlar el espacio urbano: la Iglesia Católica y la Municipalidad; mientras que el otro concierne a grupos de vecinos que desean apoyo y participación en la gestión cultural. Entre los primeros hay miembros de la burguesía local, profesionales y militantes políticos quienes, junto con sacerdotes de la parroquia, se han apropiado de lugares públicos centrales mediante la práctica de actos tradicionales, tanto religiosos (fiestas patronales y procesiones) como populares (ferias y desfiles) y la formulación de un marco legal regulativo del territorio (Plan Regulador, Plan de control de zona patrimonial). 

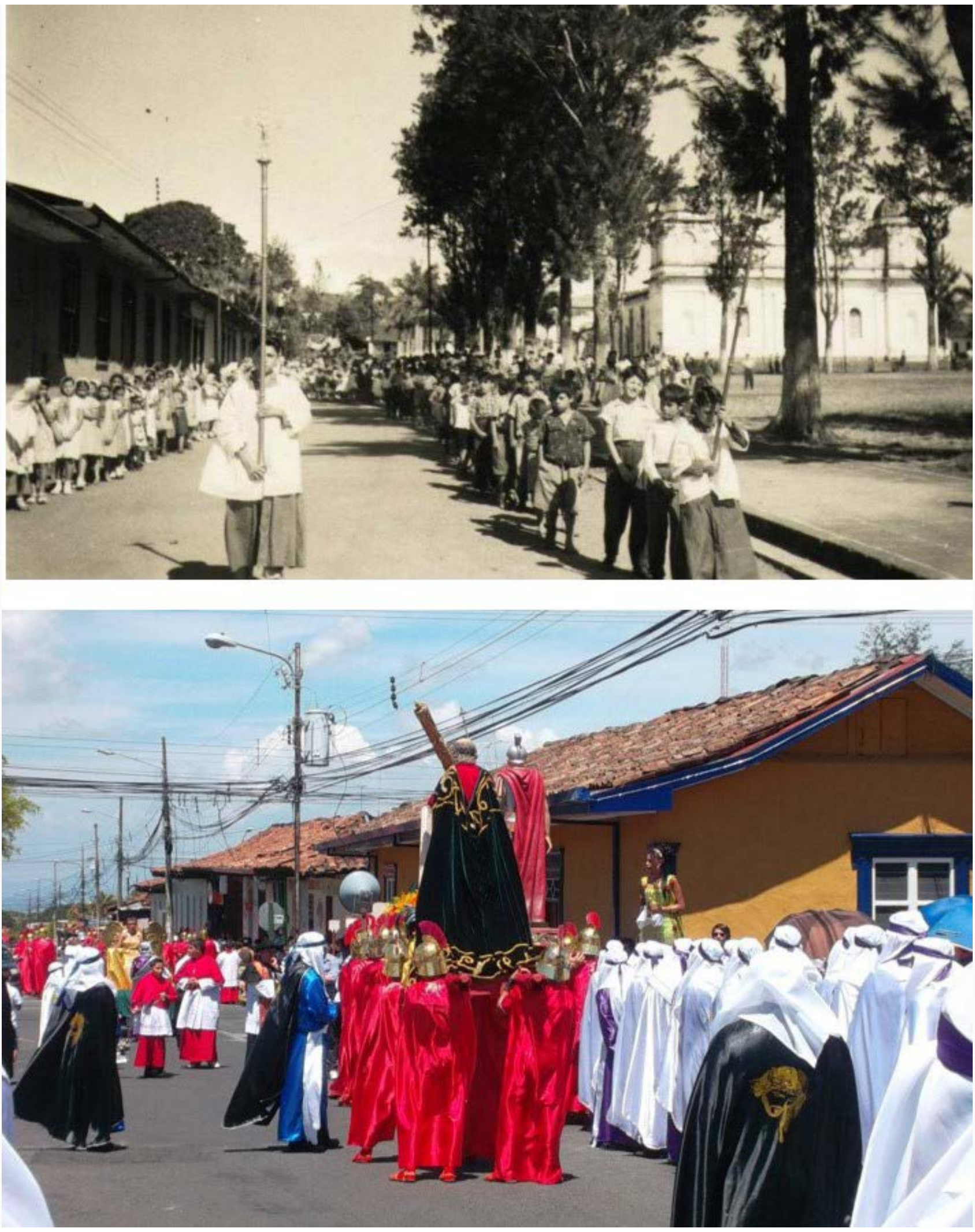

Figura 5. Procesiones tradicionales de Semana Santa en la Avenida 1 de Barva: foto superior mitad del siglo XX, foto inferior año 2012. Fuente: recuperadas de https://www.facebook.com/hernan.carballorodriguez/photos_albums, 2015.

En los segundos hay barveños que comparten el deseo de rescatar costumbres pero que no gozan de una vasta y constante exposición dentro del cantón. En algunos casos sus integrantes se han organizado en Asociaciones (como la Cultural Banda Sinfónica de Barva y Barva Escultórica) y en otros su congregación se hace espontáneamente ante la celebración de un evento simbólico relevante, y en ambas situaciones, sus manifestaciones se hacen en lugares públicos para visibilizar su acción. A modo de ejemplo se tienen los pasacalles que se hacen durante las fiestas patronales en las principales vías de la ciudad y los simposios de escultura, así como los conciertos de la banda sinfónica de Barva, que se realizan en la Iglesia o en el parque. 

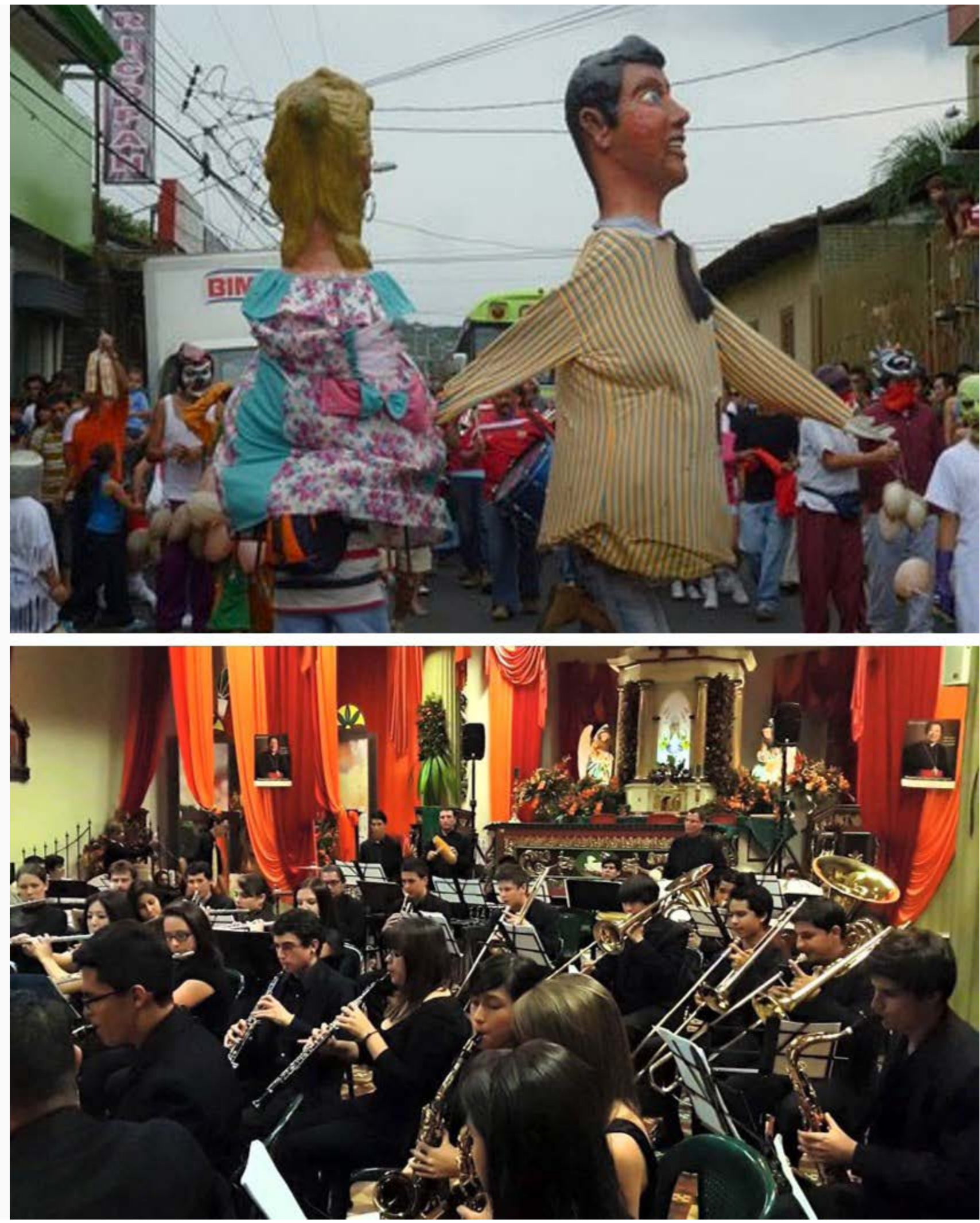

Figura 6. Celebraciones vecinales efectuadas en espacios públicos. Foto superior: Pasacalles de las fiestas patronales, década del 2012; foto inferior: concierto de la Banda Sinfónica de Barva en el templo católico del cantón, 2015. Fuente: imagen superior recuperada de https://www.facebook.com/BarvaYSuGente/photos/a.336117699812324.78730.33315511 6775249/336117713145656/?type=3\&theater, 2016; imagen inferior tomada de https://www.facebook.com/RadioBarva/ photos/pb.167818723331510.-2207520000.1464033958./814818551964854/?type=3\&theater, 2016.

e) Representaciones sociales dan un sentido de orden y arraigo a la comunidad. En este capítulo, se analizaron representaciones sociales extraídas de entrevistas realizadas a ocho informantes locales y de conversaciones espontáneas realizadas con personas de la comunidad durante las visitas al sitio. Las personas entrevistadas fueron referenciadas como líderes de organizaciones, ligadas al quehacer comunal y con gran arraigo al cantón, razones por las que se considera exponen los modos de 
pensar de distintas asociaciones locales. De sus aportes se definieron temas que fueron catalogados en cinco categorías: espacios y sitios, nombre del lugar, apellidos, nombres propios e identidad local. De la lectura de las expresiones, en cada uno de los grupos, se determinaron cinco tipos de discurso según la orientación de las alocuciones: político, comunal, histórico, inmobiliario y municipal para, finalmente, formular una hipótesis sobre su efecto en la percepción de la ciudad. Los hallazgos de este ejercicio se describen a continuación:

Sobre espacios y sitios, los discursos otorgan gran valor al centro (histórico y urbano) de Barva como espacio contenedor del legado cultural de la comunidad. En relación con nombre de lugar, expresan una forma de construcción de su idiosincrasia como alteridad de Heredia, mientras que, en identidad local, exaltan las manifestaciones artísticas y artesanales como rasgos de su identidad. En lo correspondiente a apellidos y nombres propios revelan el rol que tomaron personajes en la configuración territorial del distrito: las cuadras centrales son "personificadas" al señalarse como los asentamientos de familias específicas (la mayoría mestiza); y los nombres citados -además de referentes de agentes hegemónicos - señalan los recintos donde se localizan o han vivido y son, además, puntos para la ubicación en la ciudad (hitos urbanos).

De la examinación de la información, se obtuvieron elementos simbólicos que dan sustento a ideas, valoraciones y conceptualizaciones del ciudadano con respecto a su entorno y que guían su accionar. Del análisis de estos recursos, destacan dos claros efectos en el espacio urbano:

- Legitimación del Locus. Este sitio representa el reservorio patrimonial de la comunidad que resguarda la memoria histórica. Es el medio de articulación social porque alberga lugares simbólicos asociados a instituciones, familias y personajes emblemáticos. Es el escenario donde se llevan a cabo hábitos que se sienten, se formulan y se proyectan como rasgos identitarios que reafirman el ser local.

- Control del Locus. También, se reconoce como un espacio de alto valor como sitio de enunciación. Por tal motivo, ante existencia de formas de apropiación que denotan un nuevo estilo de vida, se representa como un territorio vulnerable, el cual requiere de políticas de regulación para su resguardo. 


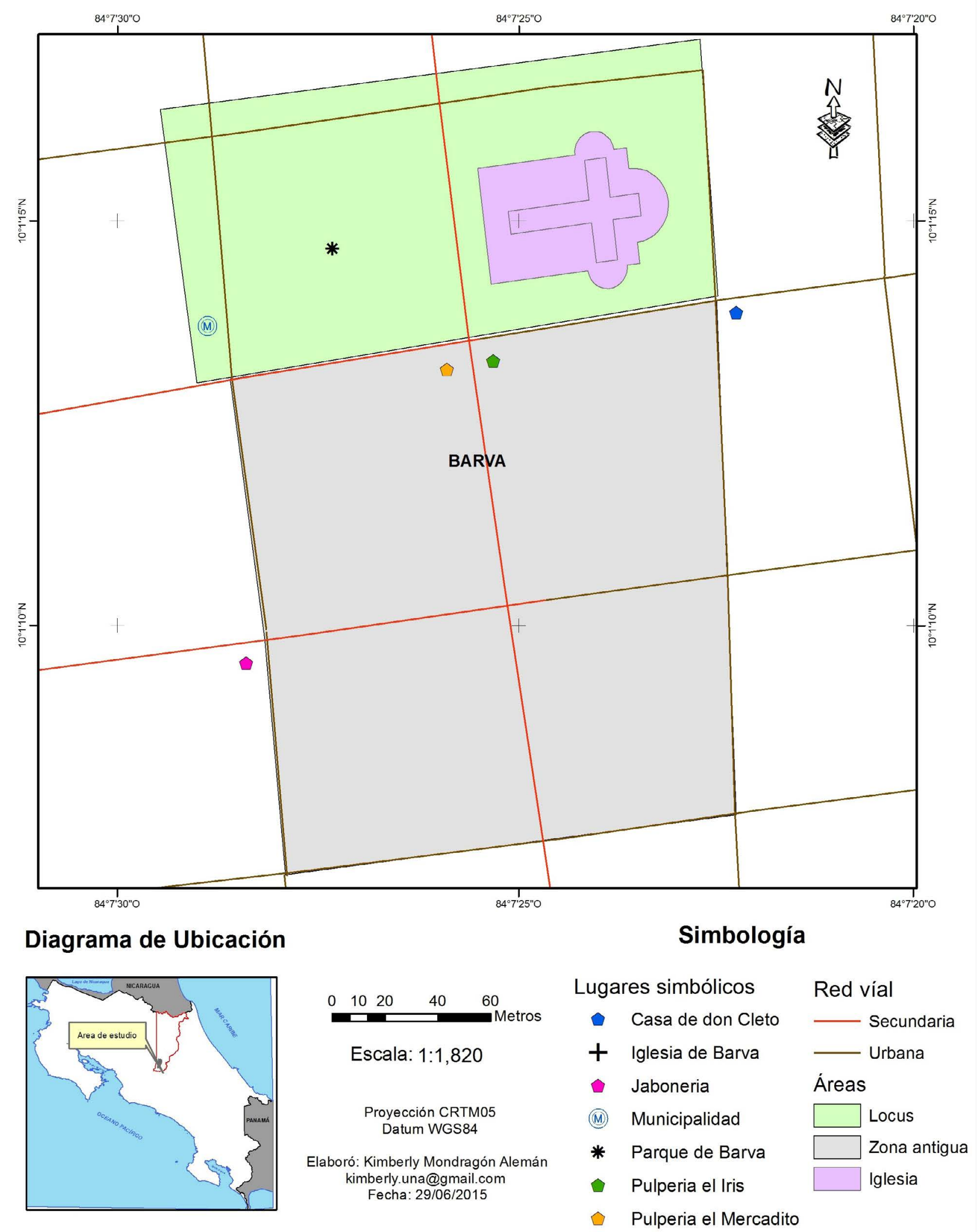

Figura 7. Ubicación de los espacios simbólicos. Fuente: Disposición de sitios y delimitación zonal según testimonios de informantes claves de la investigación. Elaboración propia, 2014.

f) Las modificaciones arquitectónicas como expresión de la transformación social de la ciudad. En este apartado se exploró el cambio en la composición urbana desde dos perspectivas:

- Una indicativa de las prácticas cotidianas de moradores que permitieron establecer conexiones emotivas que derivaron en un fuerte arraigo local y donde los espacios arquitectónicos destacaron. La Iglesia permitió el uso lúdico y espontáneo de sus jardines y fungió como escenario de actos culturales y religiosos solemnes en su interior; la plaza habilitó eventos populares que congregaba al pueblo, mientras que 
el edificio municipal fue el sitio para legitimar posiciones políticas e ideológicas ante la comunidad. La calle fue una prolongación de la vida familiar, la pulpería el sitio para socializar y hacer trueques, y hubo casas que han sido referentes geográficos y emblemáticos de la idiosincrasia barveña porque pertenecieron a figuras políticas y religiosas que dejaron su impronta en el pueblo.

- Otra, a partir de una óptica más general, atiende la mutación de la estructura territorial del cantón el cual, entre 1945 y el 2014, aumentó su área urbana 20 veces desarrollándose radialmente alrededor de la plaza y junto a carreteras nacionales. Así, desaparecieron zonas de cultivo para autoconsumo y espacios lúdicos; se introdujeron nuevos materiales constructivos como el concreto y las estructuras metálicas que rompieron la unidad arquitectónica dada por el uso del adobe y el bahareque de las edificaciones decimonónicas; importantes espacios urbanos cambiaron su forma afectando tradiciones y hábitos: la plaza se transformó en parque y las calles se ensancharon para dar paso a un mayor flujo vehicular; en tanto que el cambio de uso de suelo residencial a comercial en el distrito central implantó un nuevo paisaje urbano donde priman construcciones con fachadas modernas y anuncios comerciales. Estas permutas incidieron en un cambio en la conducta del barveño quien se enfrenta a espacios polisémicos y una organización territorial que favorece el distanciamiento de las redes sociales locales.

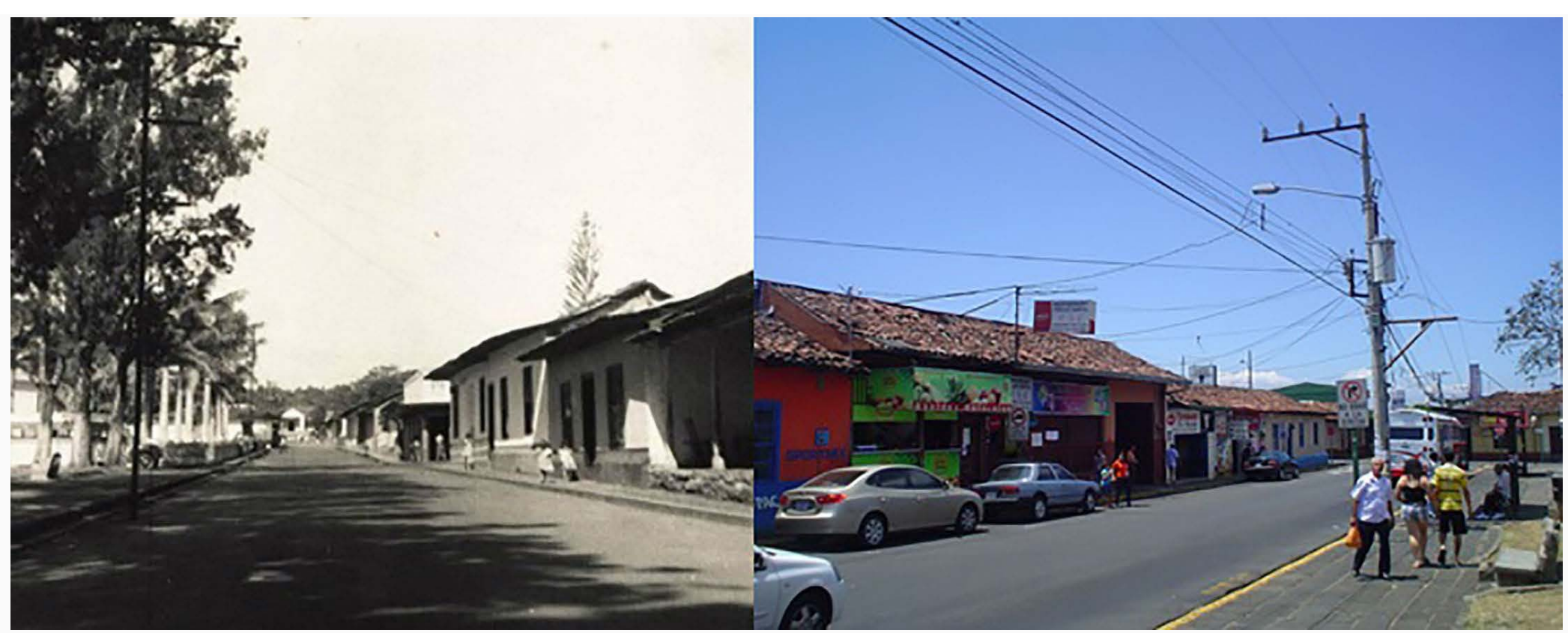

Figura 8. Fachada sur del parque de Barva en la década de 1950 y en el año 2013. Fuente: foto de la izquierda recuperada de https://www.facebook.com/photo.php?fbid=190644084386236\&set=a.190206064430038.41756.100003219381696\&type= 3\&theater, 2014; la derecha es propiedad de la autora, 2013. 


\section{Conclusión}

La investigación historiográfica reveló cómo viejos procesos sociales inciden actualmente en las dinámicas humanas de una localidad. En el caso de marras, se advirtió que la dominación ejercida por distintos hegemones desde la época de conquista y colonia española, condujo al control social y territorial mediante el posicionamiento de creencias y costumbres que se arraigaron en la mentalidad de los habitantes a través de hábitos que, por recurrencia, se fijaron como patrones de comportamiento. Esas convicciones han subsistido y hoy son parte de la idiosincrasia de Barva gracias a la gestión de lugareños que han realizado para su preservación, prácticas urbanas en espacios públicos que se han constituido en rugosidades (Santos, 2000, P.118) de su distrito central.

Estos ejercicios se han acentuado recientemente y se consideran expresiones de una reafirmación identitaria que surge, de instituciones locales y antiguos vecinos, como respuesta ante cambios morfológicos urbanos ocurridos en las últimas décadas del siglo XX y que han provocado el incremento y la diversificación de la población. Esta metamorfosis se lee en el paisaje, en el uso de la tierra y en su ordenamiento, corroborándose la pertinencia de abordar el análisis de la constitución urbana como gesto de la forma social.

El estudio realizado es una reflexión histórica sobre la reciprocidad entre el ser humano, su espacio y sociedad. Se apoya en la arquitectura para dilucidar, además de las estrategias y prácticas urbanas de actores interventores en la urbe, las representaciones sociales de una cosmovisión que han primado en el proceso de subjetivación individual y colectiva del barveño y con las que ha construido el imaginario de su comunidad. 


\section{Referencias}

Aragón, B. (2011) El cambio en las áreas boscosas de San José de la Montaña. 189o-200o (Trabajo final e inédito del taller de investigación del bachillerato en Historia). Universidad Nacional, Heredia, Costa Rica.

Araya, S. (2002). Las representaciones sociales: Ejes teóricos para su discusión. San José, Costa Rica: Facultad Latinoamericana de Ciencias Sociales.

Bielza de Ory, V. (2011). "El tema de la morfología urbana en la historia del pensamiento geográfico." Geographicalia, 59-60, 27-45. Recuperado de: https://dialnet.unirioja.es/ servlet/articulo?codigo $=3937995$

Bolaños, M., \& Valverde, N. (1978). Barva y su artesanía tradicional: un legado indígena. San José, Costa Rica: Ministerio de Cultura, Juventud y Deportes.

Carvajal, G. (2005). La organización del espacio urbano de la ciudad de San José: Temas y problemas a inicios del tercer milenio. San José, Costa Rica: Editorial Librería Alma Mater.

Castells, M. (1974). La cuestión urbana. México D.F, México: Siglo veintiuno editores.

Dirección General de Estadística y Censos (1953). Censo Nacional de Población de Costa Rica de 1950. San José, Costa Rica.

Dobles, L., \& González, C. (1934). La provincia de Heredia. San José, Costa Rica: Imprenta y Librería Lehmann.

Eco, U. (1978). La estructura ausente. Barcelona, España: Editorial Lumen.

Fernández, L. (1976). Colección de Documentos para la Historia de Costa Rica. Volumen III: Asentamientos, Hacienda y Gobiernos. San José, Costa Rica: Editorial Costa Rica.

Harvey, D. (1977). Urbanismo y desigualdad social. Madrid, España: Siglo XXI de España Editores, S.A.

Malavassi, R. (2008). "Órdenes franciscana y mercedaria en la Diócesis de Nicaragua y Costa Rica en el siglo XVIII: su arquitectura y la ocupación del espacio." $9^{\circ}$ Congreso Centroamericano de Historia. Recuperado de: http://historia.fcs.ucr.ac.cr/articulos/2008/especial2008/ articulos/03-Colonial/35.pdf

Oyón, J.L., \& Serra, M. (2009). "Historia Urbana: el espacio no es inocente." Revista Historia Contemporánea, 39, 387-402. Recuperado de: http://www.ehu.eus/ojs/index. $\mathrm{php} / \mathrm{HC} / \mathrm{article} / \mathrm{view} / 2368 / 1968$.

Sánchez, R. (2004). "Horacio Capel. Morfología de las ciudades." Vol.1. Sociedad, cultura

y paisaje urbano. Revista de Geografía Norte Grande, 32, 119-122. Recuperado de http://www.redalyc.org/articulo.oa?id=30003209.

Santos, M. (2000). La naturaleza del espacio. Barcelona, España: Editorial Ariel, S.A.

Solera, G. (1964). El Cantón de Barva. Apuntes Históricos de su Fundación y Progreso 1562-1964. San José, Costa Rica: Imprenta Nacional. 
Este artículo forma parte de:

\section{REVISTARQUIS}

Para más información, artículos, e instructivo de publicación, visite:

www.arquis.ucr.ac.cr/revistarquis.html 